\title{
A Snapshot of Role of Newspapers in the Contemporary Newspeak:
}

\author{
${ }^{1}$ Dr. Malik Zahra Khalid, ${ }^{2}$ Dr. Aaliya Ahmed* \\ ${ }^{1,2}$ Sr. Asst. Professor Media Education Research Centre University of Kashmir
}

\begin{abstract}
Newspapers are the main source of disseminating information. They play a key role as agendasetters in modern society. The function of newspapers in publicizing issues by giving in-depth view on issues like women, environment, poverty is very significant. Press as one of the pillars of democracy plays a constructive role in the national development. Speed, techniques and nature of news delivery have changed but the basic purpose of news and newspapers has remained constant and enduring. Revolution in technology, conglomeration and globalization have led to a paradigm shift in the nature of content and delivery of news. Because people depend on newspapers for their day-to-day information needs, newspapers should act to inform and educate people on social issues. The socially responsible press helps the citizens to be well informed on issues of immediate concern to them. Newspapers help in the emergence of public opinion and in building up of images through news reporting, expressing views, informing the public and thereby facilitating public discussion on issues of importance.
\end{abstract}

Keywords: Newspaper, information, public opinion, national development, social issues

\section{Introduction:}

One of the objectives of a newspaper is to understand the popular feeling and give expression to it; another is to arouse among the people certain desirable sentiments; the third is to fearlessly expose popular defects (Mahatma Gandhi ,Harijan, May 25,1946). Newspapers attempt to provide the facts and analysis that allows informed citizens to make effective and responsible decision in a complex, information-saturated society. The role of newspapers has evolved in response to the changing needs of their readers and is currently going through a softening of news in reaction to other media's coverage of lifestyle, entertainment and so on.

The press in developing countries, therefore, serves a multiplicity of purposes. It is a medium of news, the source of information about world, national and local events and means of establishing mutual understanding. It is an instrument of education, contributing to the development of human resources and capital in promoting economic growth. It is a multiplier in the communication process, spreading widely and rapidly information which will aid national development (Sommerland, 1981). Nash (1998) argues that competition for audience is driving trend toward trivial news, by chasing the passing whims of focus groups and surveys, most newspapers have shriveled coverage of major political, economic and social issues in favor of soft features, personality profiles, hoe to advice and focus on the process rather than the substance of governance .

The past few years have brought in changes in the face or look of the newspapers, several new tools have become available in the hands of newspaper designers, page makers and editors. More visual content in newspapers- pictures, graphics, color photographs and a change in the way display ads are used- can be constructed as a result of the influence of the visual media. Indian newspapers have become visually a lot more appealing, in response to the growing popularity of electronic news channels and infotainment news channels. A newspaper is a vehicle for transmitting news and ideas. The design is an integral part of that process. Every newspaper must be quite clear about its own role, its own priorities between news in depth, comment, interpretation and fun. How news is displayed and news content is created is also an offshoot of this influence of visual media on the print.

Yet another pointer to the trend of non-metro areas leading in newspaper circulation is the size of newspapers involved. While big publishing houses dominate in metro cities, medium and small newspapers with their local content are popular in small towns and rural areas. While it is true that the growth of television news has not cut into circulation figures of newspapers, as it was feared a few years ago, we don't know factors responsible for this growth of the printed word. One obvious reason is the rise seen in literacy rates in many parts of the country. Nevertheless, literacy is a key driver. Second factor is newspapers have become affordable compared to other mass commodities. Barring a few newspaper, prices have tumbled to the level of two rupees and so on.

The era in which we live is often distinguished by reference to predominance of the media in our society. A variety of words for example, 'information', 'communication', 'media' and 'digital' are used interchangeably to label the age in which we live. Such familiarity breeds contempt as we blame the media for 
many of our social problems. But the term becomes elusive on definition. According to Meyrowitz (cited in Williams,2003) the 'most glaring problem for media studies' is that there is 'no common understanding of what the subject matter of the field is'. He criticizes the media scholar for their failure to explicitly confront the nature of the media, arguing many have simply adopted 'the belief that everyone knows what the media are and that one can therefore move immediately to other research questions'.

The modern challenges are to make newspapers work as both profit centers for business and vehicles of knowledge for targeted customers. Meeting these challenges require (1) rigorous corporate and editorial governance, (2) accountability within the enterprise and to the community, (3) clear demarcation of core goals, values and functions, and (4) sharply defined market segment. Corporate and editorial governance go to the core of newspaper reason for existence but their relationship is like that of squabbling twins. Corporate leaders derive their duties from investor's right to profits while editors derive their duties from reader's right to know. The reader's right to know often places editors on a collision course not only with the corporation but also with the governments, politicians and tycoons. Where is the green line in corporate governance between the needs to make money and to produce the best editorial product? (Khindaria,2004)

\section{Role of Press in Modern Society:}

Vajpayee (The Times of India, 2000) says newspapers were destined to play a crucial role in shaping ideas and sensibilities and that the press should undertake this responsibility with a sense of mission. He says that a newspaper was not an assembly-line-production or a factory made commodity. There cannot be an alternative to a well planned managerial strategy. The press should inform, provoke debate, and even entertain. But it should refrain from distorting facts or sensationalizing events to attract readership. Restraint is needed while reporting sensitive incidents. While, zealously guarding facts, a newspaper should have an imprint of ideas on the conscience of its readers. Such deeply- embedded ideas will inspire people to meet a crisis situation. Pointing out that language newspaper has greater and more variegated role to play, Vajpayee says the responsibility of the media is commensurate with its larger role in the socio-political milieu of the country.

The role of press in society advanced by the pro-government campaign is summarized as follows;

a) The advocacy of a cooperative role for the press in nation building and national development.

b) The role of the press as a catalyst for social and political change and

c) The duty of the press to

i) Educate instead of merely entertaining.

ii) Maintaining social stability and racial harmony.

iii) Aid in economic development and nation building.

These roles are prioritized in Asia largely in line with Social structures b) political systems and c) cultural sensitivity and traditions d) economic conditions and historical perspectives in Asia. The newspapers have a two-step function. First, newspapers select certain events to attract the attention of the policy-makers and set an agenda for public actions; second, newspapers also frame the issues, telling the readers what is important to know (Murthy,2006). Following the church, legislature and executive, the press is referred as the fourth estate or pillar of democracy due to its immense growth and outreach, which has created new uses and possibilities that harbor change in society. In contemporary times, journalism has evolved grown, expanded and departed from its spirit and mission of hard core professionalism to crass commercialization. While yielding to pressures of the changing markets, the press, too, has shifted its priorities and goals.

James Augustus Hickey has the credit of launching the first newspaper in India in the shape of "Bengal Gazette" or "Hickey's Gazette" on 29th January,1780.It declared itself as a "weekly political and commercial paper open to all but influenced by none". However, Hickey's paper was closed down after two years on government orders. Publication of several newspapers followed but they had a short span of life. In postindependent India, the role of English press was designed and shaped in response to the needs of development and modernization of the nation. The press had the responsibility of educating the masses about the functioning of administrative, legal and other departments of the government. In addition, their job was to promote communal harmony in the wake of 1947 partition.

\section{Changing Approaches to News:}

It is often said that the rise of the 24-hour news culture has changed the very nature of what people seek from newspapers. Brighton and Foy (2007) have already observed the wide spread assumption that many readers are looking less to find out what has happened than help them to make sense of it-or simply to find out more detail. It may also be that we consciously or unconsciously seek aids to help us decide our options what news is, though the general consensus is that fewer people read editorials than news pages. Research on voter behavior also tends to show a very fluid relationship between readers voting habits and the political persuasion of the newspaper they choose. The spread of newspaper in a democratic country tends to reflect the spread of 
political views within the populace and although there are some practitioners within the industry who would like to feel that they are influential agenda setters, this is rarely true. Even in (the ever shrinking number of) overtly illiberal and dictatorial states, it has traditionally had little impact on altering the mindset of its readers.

A mass society is characterized by greater reliance on the mass media for information and news about the environment in which the people live. The news media are the main sources of local, national and international news. They set their agenda for public debate and create issues. In short, mass media help in the emergence of public opinion and in building up of images through news reporting, expressing views, informing the public and thereby facilitating public discussion on issues of wider concern. As a matter of fact, the mass media play significant role in the socialization of its members -their attitudes, preferences and mannerisms.

An appreciation of how and why we should analyze media content is important for a number of key reasons. First, media content is a powerful source of meaning about the social world. Second, while media content does not equate with social reality, it is essential that we examine how media content represents, or more accurately 're-presents' the realities involved in social, economic and political relationships (Devereux, 2003). The availability of new media is altering people's media habits. The press is increasingly responsible for supplying the information and image through which we understand our lives. For any social movement, the media play a crucial role in shaping public consciousness and public policy. A survey of newspapers and network programs found that men wrote about two-thirds of the front page stories (Bridges, 1989).

Merill (1995) added that the press not only reflects the ideology of the system in which it functions, but supports it and cannot exceed the system's limits. As a result, the main category for systematization has been the different societies' political perspective on government- press relation and this has often resulted in confusion between 'the actual working principles of a given media system; the theoretical ideals of the system and the dominant ideology of the society (capitalist, socialist, revolutionary, developmental or whatever)'.

As a result of opening up of the market to more competition, consumers, it is argued, will be provided with a greater range of products as companies compete with each other. The emergence of more channels and outlets, increased access to information and knowledge, and more control over when and what people watch and listen to appears to confirm the argument that the free market brings more choice for the individual. Thus any concerns about increased concentration of ownership are offset by more choice. Supporters of the 'free market' see the explosion of choices making redundant old-fashioned anxieties about media monopoly as deregulation encourages competition, investment and a growing diversity of product.

From financing a newspaper to defining news in the changing dynamics of new technology and organizing the news process, newspaper executives have been involved in devising approaches so as to make news and newspaper very attractive for people now and in the future too. Many newspapers are now using colorful and attractive layouts with eye-catching graphics. Also reporting on the communities in which the readers of the newspaper live helps the newspaper and encourages people in their areas to see them as related to their lives on a regular basis. Digital newspapers also have appeared on the scene which has helped in catering to the information need of the diasporic audience. The challenges are daunting as the internet user can go to any other site for news that newspaper risk losing its readers.

Along with the dominant stream of journalism obsessed with politics and concerned with urban issues and developments there have been some strains in Indian Journalism as well. The Hindustan Times can claim some credit for starting development reporting. In the 1950's extensive reporting about the functioning and the problems of various public sector projects in India was undertaken by the Hindustan Times (Yadava,1998). India was much ahead of all developing countries in creating an awareness of the role of communication in nation-building and development. It was also much evolving a broad perspective and strategy for communication planning suited to the goals of national development and social transformation in a country of sub continental size and diversity and long historic tradition (Joshi, 1998:206). For Gandhi, the key to a newspaper's role in arousing social awareness was integrity and credibility. Social commitment was basic. Transparency in all its operations was essential to maintain its reputation (Bhattacharjee.2003).

Oetama (1989) likewise points out that the press cannot stand outside of society, but must exist within it and thereby be influenced by its currents and fundamental structures. Although the press plays an active role in shaping society, it can never become an autonomous power, it is significant only in terms of other institutions and it is invariably influenced by the main currents and structure of society. The press has a role in surveying and interpreting the environment for individuals in society. To perform this role, according to Oetama (1989), it must necessarily have a certain value system and this value system can only come from a critical and deep awareness of the social context and dynamics and from reflection.

The relationship of the press with the government primarily depends on the existing political order. In countries, which espouse liberal democracy, the press has evolved as an independent institution (the fourth estate) acting as a moderator or watchdog on behalf of the public. In socialist and authoritarian states, the press is regarded as an 'ally' of the state and in some instances the mouthpiece of the government. Romano (1999) citing the Indonesian media theorist Ashadi Siregar notes that most discussions by academics, bureaucrats and 
journalists about this country's press have been of a normative nature. Normative theory identifies dominant social values and how the mass media should ideally operate if they are to encompass such values.

It is the asymmetry of the flow of news based upon the asymmetry in the distribution of world power that is being challenged by the Third World which argues that

1) There may be supplementary or corrective news values criteria that have not been identified or tested through the services aimed at the public of primarily industrialized countries.

2) There may be an urgent need now for recognizing the dispersion of power centers that the established institutional routines are slow to identify.

3) There may be a case for trying through public-sector initiatives to identify new demands and to create institutions and outlets that will satisfy those demands (Naesselund,1991)

Field reports involve field study. They draw attention to underline social processes, not daily events. They are remembered longer and provide a reliable index of the health of the society. While, competition for circulation between newspapers has led to dumbing down of content, competition with 24-hour news channels has induced rethinking on news priorities. TV channels have cut into the advertisement revenues and circulations. Newspapers can no longer attract readers by headlining the latest spot news, not to speak of breaking news that they have already heard and seen it on TV.

\section{Journalism in Kashmir:}

Growth of newspapers in the state is an indicator of the fact that the readership has increased and people want variety, substance and professionalism in the content. The content of the newspapers have to be responsive to the changing demands of different sections of the society. The real challenge for the newspaper today is to cater to the ordinary class of people, discussing their issues and concerns. Newspapers have emerged as a credible source of information for the majority of people. People pick up the early newspaper to scan the latest issues and problems being faced by the state. Through its editorials and lead articles the modern day newspapers have the responsibility of shaping and moulding the public opinion rather than it being a concept confined to text books only. With the proliferation of the newspaper industry, it becomes all the more pertinent for the newspaper to cater to the different tastes of its audience.

In a situation like Kashmir, the press, indeed, can play a pivotal role. Besides the role of watcher, teacher and forum, it can further the peace process through its discourse analysis. The development debates have been placed on a back burner due to the prevailing conditions in Kashmir. However, in addition to reporting news stories, it is inevitable that the press should also act as a mirror, constructive critic, expose corruption and provide a platform for investigative and interpretative journalism. Coverage to such topics as health, education, agriculture is unfortunately minimal and if even any is based on the official handout.

Due to the lack of financial assistance from the government or big business and corporate houses, the support required by the newspapers to thrive is not there. Advertisements are there but they are few and certainly not enough to bring a 20-page daily newspaper. Readers are highly selective, exclusive and perhaps rigid in their preference and choice of media vehicle. Demands of the market have to be closely monitored and creatively responded to by all those involved in print journalism.

The feverish pitch at which newspapers are being launched in the valley is matched by an equally fervent desire to use the medium for partisan ends. In the process, professionalism receives a big blow through the influence of political and bureaucratic brass. More newspapers mean more diversity and dynamic vigor into the dissemination of news and information rather than it being a mouth piece of hegemonic elites of the society. The perceptual mapping of the audiences as consumers of the media fare cannot be undermined or ignored. As the consequence of conflict, there has been a spurt of newspapers, both English and vernacular. On the other hand in Jammu, there has been an increase in the number of newspapers but not to the same extent as in Kashmir valley. Content diversification and presentation is more appealing and effective as compared to the local newspapers.

The opportunities are galore and persist to be exposed and exploited. Rather than being commercial in their approach and perspective, the vernacular press needs to promote more professionalism. Sense of seriousness and improved qualitative measures need to be implemented. Revolutionary change in the design and layout could enhance the attributes and value of a newspaper. With technology making rapid advances, press could emerge as a strong weapon for giving competition even to the national newspaper. Sensationalism of news and departmentalization of news are two areas where the press particularly vernacular needs to focus more diligently and emphatically. Ambiguity is prevalent in news stories. News value finds no place in the vernacular press.

Vernacular press has a considerable reader-ship considering the literacy of the state. Though it has lost its essence and glory of its formative years, it still has been able to sustain itself. The reason for the missed opportunities could be many- insignificant news content, dull layout, cramped news stories on front page, 
sensational reporting, not responsive to the changing needs and trends of the society. News is mutilated and amplified by the people who are at the helm of affairs.

In a situation like the one prevailing in Kashmir journalism has a challenging task to redefine and reinvent itself. There is a hot debate whether in the present context of situations, journalism should stick to the ethics set by people hundred years back in different situations or set new ethics to remain on the side of the public. The debate gained more prominence and momentum after 9/11, Iraq and Afghanistan engagement of the United States. United States is championing to be the major source of liberty and fearless in reporting but in the past few years while the newspapers published from J\&K came under severe criticism for not reporting the truth post 9/11 and about the real situation in Iraq and Afghanistan. Should national interests be the grounding force while reporting from a conflict zone or should truth be the main force to report even if it hits national interests? In this pendulum of swirling interests, questions of truth and national int condensing the profligacy and can be used to mould the public attitude and thinking towards the betterment of society.

Circulation nowadays is the oxygen for the survival of newspapers, and the paper adopts new strategies to do so.

The chief reason for the trend of commercialization is the entry of big business houses into the profession of journalism. These business houses go for sensationalism to get maximum gains. Veteran journalist Chalapati Rao says the broad feature of Indian Press is that it is an industry now, which is managed and owned by other industries. The working class, the poor peasant does not exist for mass media (Naesselund, 1991).

In a situation like Kashmir, the press, indeed, can play a pivotal role. Besides the role of watcher, teacher and forum, it can further the peace process through its discourse analysis. The development debates have been placed on a back burner due to the prevailing conditions in Kashmir. However, in addition to reporting news stories, it is inevitable that the press should also act as a mirror, constructive critic, expose corruption and provide a platform for investigative and interpretative journalism. Coverage to such topics as health, education, agriculture is unfortunately minimal and if even any is based on the official handout.

The press as one of the pillars of democracy plays a constructive role in the national development. To play such a crucial role in development, the press was expected to create awareness among the people. Despite turmoil Kashmir like any other place in the subcontinent is witnessing silent social upheaval and distinctive changes within. The hidden hands of nature and changes together are weaving a new Kashmir beneath, totally away from the eyes of media. There is little mention of such changes in the reports of Kashmir based journalists. The media play important roles in society.

As a fourth estate, they provide checks and balances on the activities of the three arms of government; as agenda setters, they influence the issues on public agenda; as gatekeepers, they decide what information gets to the public; as watchdog, they represent the interests of the people and as multipliers, they add to multiply messages. The positive role of media in national development has been recognized in the Third World countries because information dissemination plays a key role in bringing social change among the receivers. Besides being a powerful news gathering and news disseminating platform, media is an institution with a deep social foundation. A relationship of reciprocity between media and society lends it the strength it enjoys. Whether print or electronic, media in its appeal is massive and profound. From individual behavior to social norms, the gamut of media is vast and deep. Electronic media being more picture oriented carries more sensational and glamour. In comparison print medium is serious but lasting. Despite the abundance of television channels which leave hardly any time to breathe at ease, newspapers still continue to be the effective sources of communication.

\section{Conclusion:}

A magnificent gift to the mankind and highly indispensable, press does a splendid job, performs a crucial role as a communicator. Because of its importance and significance, it has been highly acclaimed, admired and appreciated. And it won't be unpalatable to say that what air is to living beings, the Press is to society. In this apparently free press scenario the question remains that what issues get prominence in the press and why are others relegated to the back pages.

The journalist being aware of their role can influence their audience and attract their attention to cooperate and participate in more equitable developmental plans. Narinder Aggarwala, an Indian journalist who advocates development journalism, believes that journalists at the development desk should critically evaluate all developments plans from national and local perspectives. A news report fulfills the minimum criteria for development journalism if it consists of at least one of the following points: stresses the process and not the event, maintains a critical perspective on development plans, emphasizes people's needs, presents a background for development issues, predicts future needs, considers the effect of plans on people, compares the development process to similar processes in other places, compares the plan with implemented results, critically surveys stories of success, and points out people's needs.

Politics, as we have been experiencing all along, is the staple of newspapers. But this is not all; other issues merit an equal mention. Do other developmental issues get appropriate coverage or they get eclipsed under a huge cover of politics. These questions assume more importance when it comes to the coverage of 
developmental issues by print media. Enormous space is given by our media to business, and very little to social sectors like health and education. Most media correspondents attend the film stars, fashion parades, pop music, etc. and very few attend to the lives and problems of workers, farmers, students, sex workers, etc. That's why Lakme Fashion Week scores so heavily over farm suicides.

With color comics, syndicated columnists, hefty sports sections, photograph filled Sunday magazine, and more, the newspaper has become a mosaic of features designed to attract as many different types of people as possible. A newspaper in a developing country ought to turn its attention quite frequently to various problems facing that country instead of being obsessed with the politics and glamour. There are major problems facing India and the state of Jammu and Kashmir. A socially responsible press will turn its attention frequently to these problems and takes a crusading attitude towards their solution. There are important roles that newspapers can play in the life of society that are not duplicated by other existing sources. To ensure the future of newspapers, though, it is necessary to make these roles clear, to pursue them and to find ways to support them. This is the profound challenge that the newspaper industry will have to confront for years to come.

\section{References}

[1]. Bhattacharjee. Ajit. (2003a). Gandhi’s media Values. Vidura, 40 (2).p.21.

[2]. Bridges, J. A. (1989). News use on the front pages of the American Daily. Journalism Quarterly, 66 (2): pp. $332-334$.

[3]. Brighton, Paul Foy, Dennis. (2007). News Values. London: Sage Publications Ltd.

[4]. Devereux, E. (2003). Understanding the Media. London: Sage Publications Ltd. pp. 116-130

[5]. Khindaria, Brij. (2004). Print Journalism at the crossroads. Vidura: 41: (2): pp. 4-6.

[6]. Merill, J. (1995). Global Journalism. New York: Longman.

[7]. Murthy, D. V.R. (2006). Developmental Journalism. New Delhi. Dominant Publishers. P. 105

[8]. Nash K.(1998). Trivia Pursuit: How showbiz values are corrupting the news. Toronto: McClelland and Stewart.

[9]. Naesselund, Gunnar R. (1991). UNESCO and the press in the Third World in Horton, Philip C. The Third World and press freedom. New York; Praeger. pp 211-217.

[10]. Oetama. J.(1989). The Press and Society. In A. Mehra (Ed). Press system in ASEAN states. Singapore; Asian Media Information and Communication Centre. pp 135-146.

[11]. Rau Chalapathi.(1980) 200 years of the Indian Press. Vidura, February.

[12]. Romano, A. (1999). Development Journalism: State vs. Practitioner Perspectives in Indonesia. Media Asia, 26 (4): p 183-186.

[13]. Sommerland, E. L.(1981). The Press in Developing Countries. Sidney: Sidney University Press.

[14]. Williams, Kevin. (2003). Understanding Media Theory. London. Arnold. p 4

[15]. Yadava, J. S. (1998). Is Western model relevant to Asia? In Yadava, J. S. and Mathur, Pradeep. Issues in mass communication: the basic concepts. Vol. 1. New Delhi: Kanishka \& Indian Institute of Mass Communication. pp 134-136 